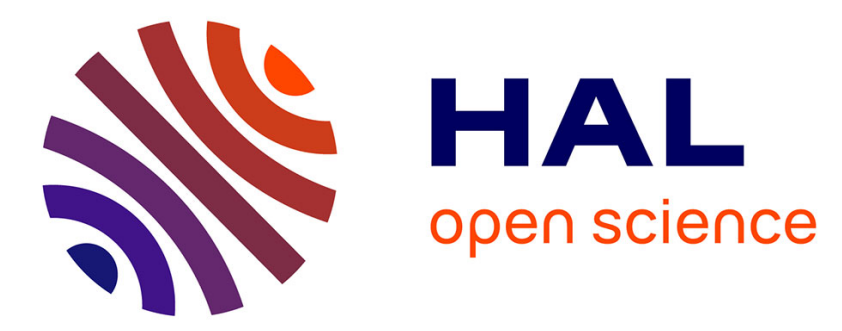

\title{
Cognitive dysfunction in lower motor neuron disease: executive and memory deficits in progressive muscular atrophy
}

Joost Raaphorst, Marianne de Visser, Marie-José van Tol, Wim Linssen, Anneke van Der Kooi, Rob de Haan, Leonard van den Berg, Ben Schmand

\section{To cite this version:}

Joost Raaphorst, Marianne de Visser, Marie-José van Tol, Wim Linssen, Anneke van Der Kooi, et al. Cognitive dysfunction in lower motor neuron disease: executive and memory deficits in progressive muscular atrophy. Journal of Neurology, Neurosurgery and Psychiatry, 2010, 82 (2), pp.170. 10.1136/jnnp.2009.204446 . hal-00557447

\section{HAL Id: hal-00557447 https://hal.science/hal-00557447}

Submitted on 19 Jan 2011

HAL is a multi-disciplinary open access archive for the deposit and dissemination of scientific research documents, whether they are published or not. The documents may come from teaching and research institutions in France or abroad, or from public or private research centers.
L'archive ouverte pluridisciplinaire HAL, est destinée au dépôt et à la diffusion de documents scientifiques de niveau recherche, publiés ou non, émanant des établissements d'enseignement et de recherche français ou étrangers, des laboratoires publics ou privés. 


\section{Cognitive dysfunction in lower motor neuron disease: executive and memory deficits in progressive muscular atrophy}

Joost Raaphorst ${ }^{1,4}$, Marianne de Visser ${ }^{1}$, Marie-José van Tol ${ }^{5}$, Wim H.J.P Linssen ${ }^{4}$, Anneke J. van der Kooi, ${ }^{1}$, Rob J. de Haan ${ }^{2}$, Leonard H. van den Berg ${ }^{6}$, Ben Schmand ${ }^{1,3}$

${ }^{1}$ Departments of Neurology, and ${ }^{2}$ Clinical Epidemiology and Biostatistics, Academic Medical Centre, University of Amsterdam, ${ }^{3}$ Department of Psychonomics, University of Amsterdam, ${ }^{4}$ Department of Neurology, Sint Lucas Andreas Hospital, Amsterdam, ${ }^{5}$ Department of Psychiatry, Leiden University Medical Centre, ${ }^{6}$ Department of Neurology, Rudolf Magnus Institute of Neuroscience, University Medical Centre Utrecht, all in the Netherlands.

Address correspondence to: Joost Raaphorst, Department of Neurology (H2-235)

Academic Medical Centre, PO Box 22660, 1100 DD Amsterdam, The Netherlands

Telephone +31-20-5663856 Fax +31-20-5669374 E-mail: j.raaphorst@amc.uva.nl

Word count abstract: $229 \quad$ Word count: 3037

There are three supplemental data files to the manuscript: Appendix A, Appendix B and a cited "in press" article.

Keywords: Motor neuron disease, ALS, progressive muscular atrophy, cognitive impairment

Joost Raaphorst, Marianne de Visser, Marie-José van Tol, Wim Linssen, Anneke van der Kooi, Rob de Haan, Leonard van den Berg and Ben Schmand report no disclosures. 


\section{ABSTRACT}

Aim In contrast to findings in ALS, cognitive impairments have as yet not been shown in the lower motor neuron variant of motor neuron disease, progressive spinal muscular atrophy (PMA). Our objective was to investigate cognitive function in PMA and to compare the cognitive profile with that of ALS. In addition, we assessed visuopatial functions comprehensively; these tests are underrepresented in earlier neuropsychological investigations in ALS.

Methods Twenty-three PMA and 30 ALS patients (vital capacity $>70 \%$ of predicted value) underwent a neuropsychological assessment adapted to motor impairments: global cognitive and executive functioning, psychomotor speed, memory, language, attention and visuospatial skills. The results were compared with age, education and sex-matched controls and with normative data.

Results Compared to controls PMA patients performed worse on attention/working memory (digit span backward), category fluency and the mini-mental state examination. Compared with normative data, PMA most frequently showed impairment on three measures: letter-number sequencing, immediate and delayed story recall. Seventeen percent of PMA patients showed cognitive impairment, defined as performance below two standard deviations from the mean of normative data on at least three neuropsychological tests. In ALS similar but more extensive cognitive deficits were found. Visuospatial dysfunction was not found in PMA and ALS.

Conclusions Seventeen percent of PMA patients have executive and memory impairments. PMA with cognitive impairment adds a formerly unknown phenotype to the existing classification of motor neuron diseases. 


\section{INTRODUCTION}

Cognitive impairments have been found in motor neuron disease patients with upper motor neuron (UMN) involvement: $30 \%$ of patients with amyotrophic lateral sclerosis (ALS), and a fair proportion of patients with primary lateral sclerosis have executive and memory deficits.[1-4] Whether this holds true for patients with only lower motor neuron (LMN) signs is unclear.[5] Progressive spinal muscular atrophy (PMA) is an adult-onset progressive LMN disorder. There is still debate on whether PMA is a distinct disease entity or whether it represents one end of the spectrum of motor neuron diseases. In favor of the latter claim are the clinical, genetic and pathologic features that PMA shares with ALS.[6-9] We therefore hypothesize that PMA patients may exhibit cognitive impairments in similar domains compared to ALS. PMA seldom starts in bulbar neurons. As cognitive impairments have been found to be related to bulbar-onset ALS in some studies, cognitive impairment may not be encountered as frequently in PMA compared to ALS.[10-12]

The main objective of this study was to explore the occurrence of cognitive dysfunction and its clinical correlates in PMA in comparison with that of ALS. In addition, we aimed to further define the cognitive profile of ALS by measuring visuospatial functions. Visuospatial test are underrepresented in earlier neuropsychological investigations in ALS and thus the presence of visuospatial deficits is unclear.[12, 13] Visuospatial dysfunction may be suspected in ALS, as patients with other disorders affecting the motor system (e.g. Parkinson's disease or dystonia) have shown visuospatial deficits. [14, 15]

\section{METHODS}

Subjects. Patients were recruited between January 2007 and January 2009 from the out-patient clinics of the Academic Medical Centre, Amsterdam and University Medical Centre Utrecht. Spouses and friends of patients were asked to participate as controls. We chose this control group to ensure that it would be matched for education and age, which are important variables that may influence cognitive measures. The medical ethical committees of the hospitals approved the study. Written informed consent was obtained from all participants. Included were PMA patients who fulfilled the criteria as earlier described 
[[6]: (1) a disease duration of less than 5 years from the time of diagnosis, (2) clinical and electrophysiological evidence of LMN involvement in two or more of four regions (bulbar, cervical, thoracic and lumbosacral), (3) no conduction blocks on nerve conduction studies, and (4) no clinical UMN-signs and symptoms, including forced yawning, crying and laughing, clonus of masseter reflex, (sub)clonic myotatic reflexes, Hoffmann-Trömner sign, extensor plantar response, or spasticity. All patients with ALS included in the study could be classified as probable or definite according to the revised El Escorial criteria.[16] Patients and controls were excluded if they had dementia according to consensus criteria (Diagnostic and Statistical Manual of Mental Disorders (DSM), American Psychiatric Association, 1994 and Lund-Manchester Criteria,[17]) a history of another neurological disorder associated with cognitive impairment, a vital capacity lower than $70 \%$ of the predicted value (to prevent bias of respiratory compromise on cognitive measures),[18] severe dysarthria or anarthria, or if they were unable to push a button with the index or middle finger of their dominant hand. Patients had to speak Dutch fluently and they had to be free of psycho-active medication.

Clinical assessment. The Amyotrophic Lateral Sclerosis Functional Rating Scale (ALSFRS-R) was used to evaluate the functional status of the patients.[19] To assess upper motor neuron involvement an unvalidated scale was used that summated myotatic and pathological UMN reflexes and pseudobulbar affect. The scale is a modification of the scale used by Ellis et al. (table 1).[20] 
Table 1. Upper motor neuron scale

Reflex, symptoms

biceps

triceps

knee jerk

ankle jerk absent

barely visible

clearly hypoactive

slightly hypoactive

normal

slightly hyperactive

clearly hyperactive, not clonic

subclonic

clonic

hyperactive or preserved reflex in

wasted muscle

Hoffmann signs
extensor plantar responses
clonus of masseter reflex

pseudobulbar affect* present

absent

one or more present

all absent

normal score $=16($ range $0-48)$

\section{score}

0

1

2

3

4

5

6

7

8

8

4
0

4

0

*Pseudobulbar affect: forced crying, laughing or yawning

In addition the following clinical variables were assessed: site of onset (bulbar of limb); degree of bulbar involvement (defined as a score below 4 on 1 or more of the bulbar items of the ALSFRS-R); disease duration (defined as the time between the first symptom and the neuropsychological assessment); vital capacity (percentage of predicted value: predVC) and the years of formal education. Neuropsychological assessment. Neuropsychological tests were administered in a fixed order with rest periods if needed. To further avoid a negative effect of fatigue the testing was done in an out-patient clinic in the vicinity of the patients' homes.

Premorbid intellectual ability (National Adult Reading Test, Dutch version, DART), global cognitive functioning (MMSE) and six cognitive domains were tested: attention and working memory, executive functions, psychomotor speed, memory, language and visuospatial abilities (for neuropsychological tests and references, see appendix A). Five tests relied on speed: Stroop test parts A (word naming), B (color naming) and C (word interference on color naming), category and letter fluency. The Stroop test part A 
was used to control for a possible negative effect of dysarthria on the fluency tests, by generating the measure fluency-motor speed corrected, according to the following formula (for letter fluency):

Letter fluency-motor speed corrected $=(\underline{180-(\text { time per } \text { word for Stroop part A }) * \text { fluency score })}$

fluency score

Where fluency score $=$ total amount of produced words with letters K, O and M in 180 seconds $(60$ per letter). The time per word for Stroop part A is the mean time (in seconds) it took the subject to pronounce a color-word. A similar formula for category fluency was used.

The Stroop test part B (color naming) and C (word interference on color naming) were not not accommodated for motor impairment. These tests were used to calculate the Stroop interference time (Stroop C - Stroop B, not motor speed dependent). The mental rotation task is described in detail in appendix B. The Hospital Anxiety and Depression Scale (HADS) was used to examine symptoms of depression or anxiety.[21]

Statistical-analyses. Differences in demographic and clinical characteristics between the PMA and ALS patients, respectively, and the control group were analyzed with a two group t-test. When data and their $\log$ or inverse transformations were not normally distributed, non parametric Mann-Whitney $U$ tests were used to analyze differences between groups. The $\chi^{2}$ test was used to analyze nominal variables. Differences between the scores of neuropsychological measures of PMA and ALS patients, respectively, and the control group were expressed in Hedge's g effect size. By convention, effect sizes of 0,2, 0,5 and 0,8 are considered small, moderate and large, respectively.[22] A second set of analyses was done to examine the cognitive deficits in a manner similar to clinical practice. Standard scores, either scaled scores (mean 10; SD 3) or T-scores (mean 50; SD 10) were derived from available normative data in test manuals. Normative scores were taken from the following sources: Stroop Color Word Test and RBMT, www.neuropsycholoog.nl,[23] COWAT and category fluency,[24] BNT,[25] MWCST.[26] 
Frequency of cognitive dysfunction. A test score was considered impaired if more than two standard deviations (SD) below the mean score of the normative sample, after correction for age, gender, and if possible, education. Cognitive dysfunction was considered to be present if performance on more than two neuropsychological tests was impaired (measures without adjustment for motor impairment (Stroop test parts $\mathrm{A}, \mathrm{B}$ and $\mathrm{C}$ ) were excluded from this analysis). This criterion ensured that less than $5 \%$ of the control subjects would be impaired. In addition, the criterion minimizes the possibility that impaired performance reflects a chance finding due to the large number of measures employed.

\section{Demographic and clinical variables associated with cognitive impairment}

To identify variables associated with cognitive impairment, ALS and PMA patients with and without cognitive impairment were compared using the following variables: age; education; HADS total score and subscores; disease duration; ALSFRS-R (including a bulbar sum-score); site of onset and predVC. A possible relation of UMN-signs with cognitive impairment was explored in three ways: firstly, performance of the PMA and ALS patient groups on the neuropsychological tests were compared. Secondly, in the PMA and ALS patients together (MND patients), the UMN-score was compared between MND patients with and without cognitive impairment. Thirdly, within MND patients correlations between the UMN-score and performance on the neuropsychological tests were analyzed.

\section{RESULTS}

Demographic and clinical characteristics. Twenty-three PMA patients, 30 ALS patients and 24 age, sex and education matched controls were included. Age, sex distribution, years of education, DART-IQ estimate, HADS-scores and the ALSFRS-R were not significantly different in patients and controls (PMA vs. controls; ALS vs. controls and PMA vs. ALS, table 2). The median sum-score of the three ALSFRS-R bulbar items (normal score =12) was 10 (range 6-11) in ALS patients and 12 (range 9-12) in PMA patients $(\mathrm{p}<0.05)$, respectively. The UMN-score was higher in ALS compared to PMA patients $(\mathrm{p}<0.001)$ 
Table 2. Demographic and clinical characteristics of patients and controls.

\begin{tabular}{|c|c|c|c|}
\hline Characteristics & PMA $(n=23)$ & ALS $(n=30)$ & $H C(n=24)$ \\
\hline $\operatorname{Sex}(m / f)$ & $17 / 6$ & $18 / 12$ & $12 / 12$ \\
\hline Age $(y)$ & $62.0(9.3)$ & $61.2(11.8)$ & $59.8(11.8)$ \\
\hline Premorbid IQ & $99.3(16.2)$ & $103.5(15.6)$ & $108.2(18.2)$ \\
\hline Education (y) & $13.6(2.5)$ & $13.8(2.6)$ & $13.9(2.1)$ \\
\hline HADS anxiety & $4.4(2.6)$ & $4.2(2.8)$ & $4.6(2.9)$ \\
\hline HADS depression & $4.1(2.5)$ & $4.4(3.5)$ & $3.5(3.8)$ \\
\hline HADS total & $8.4(4.8)$ & $8.6(5.8)$ & $8.1(6.1)$ \\
\hline Disease duration, months & $27.5(18.0)$ & $21.5(11.2)$ & - \\
\hline ALSFRS-R (max. 48) & $41.6(3.8)$ & $40.3(4.6)$ & - \\
\hline Bulbar onset, No. (\%) & 0 & $10(30)$ & - \\
\hline Bulbar region affected ${ }^{*}$, No. (\%) & $5(22)$ & $19(57)$ & - \\
\hline UMN-score & $14,7(4,6)$ & $29,7(5,7)$ & - \\
\hline
\end{tabular}

Values are mean (SD), unless stated otherwise. HC: Healthy controls. ALSFRS-R: Amyotrophic Lateral Sclerosis Functional Rating Scale-Revised. HADS: Hospital Anxiety and Depression Scale. * Bulbar region affected was defined as a score below 4 on 1 of the bulbar items of the ALSFRS-R. " UMNscore: sum score of myotatic and pathological UMN reflexes and pseudobulbar affect (range 0-48, normal score is 16 ). 
Neuropsychological performance of PMA and ALS patients and control subjects. Compared to controls, PMA patients performed worse on an attention/working memory test (digit span backward), category fluency and the MMSE. Compared to controls, ALS patients showed impaired performance on attention/working memory (letter-number sequencing), category and letter fluency, Stroop test part B (not corrected for motor impairment), visual memory and naming (table 3). Effect sizes ranged from negligible to moderate (table 3). There were no statistical differences in performance on the neuropsychological tests between the PMA and ALS patient groups. Not all patients completed the neuropsychological battery: two visuospatial tests were not performed by some patients due to fatigue, technical problems (1 ALS patient, 1 control) and disease progression (not being able to push a button) between the moment the patient decided to participate and the neuropsychological investigation (2 ALS patients, 1 PMA patient). 
Table 3. Neuropsychological test results in patients and controls: raw scores, p-values and effect sizes

\begin{tabular}{|c|c|c|c|c|c|c|c|}
\hline & PMA (n=23) & $\operatorname{ALS}(n=30)$ & $\mathrm{HC}(n=24)$ & $\begin{array}{c}P \text { value } \\
\text { PMA vs } \\
H C\end{array}$ & $\begin{array}{c}P \text { value } \\
\text { ALS vs } \\
H C\end{array}$ & $\begin{array}{r}\begin{array}{r}\text { Ef } \\
(\mathbf{H} \\
\text { PMA }\end{array} \\
\end{array}$ & $\begin{array}{l}\text { ze } \\
\text { ALS }\end{array}$ \\
\hline MMSE & $28.1(1.5)$ & $28.3(1.5)$ & $29.0(1.0)$ & .04 & .09 & -0.70 & -0.53 \\
\hline Attention/working memory & & & & & & & \\
\hline Digits forward raw score & $7.4(2.0)$ & $7.7(2.4)$ & $8.4(2.2)$ & .11 & .24 & -0.47 & -0.30 \\
\hline Digits backward raw score & $4.4(1.9)^{*}$ & $5.2(1.7)$ & $5.8(1.7)$ & .01 & .22 & -0.76 & -0.35 \\
\hline Number-letter sequencing score & $9.4(2.6)$ & $9.1(2.9)$ & $10.3(1.5)$ & .19 & .10 & -0.42 & -0.49 \\
\hline span & $5.1(1.1)$ & $4.9(1.1)$ & $5.5(0.7)$ & .12 & .04 & -0.43 & -0.62 \\
\hline Executive functions & & & & & & & \\
\hline $\begin{array}{l}\text { Stroop C word interference on } \\
\text { color naming, time }(\mathbf{s})^{\mathbb{4}}\end{array}$ & $107.1(35.6)$ & $121.4(57.8)$ & $103.3(31.7)$ & .70 & .18 & -0.11 & -0.37 \\
\hline $\begin{array}{l}\text { Stroop Interference time } \\
\text { (Stroop C - Stroop B) (s) }\end{array}$ & $52.0(25.0)$ & $52.7(40.2)$ & $47.8(27.4)$ & .60 & .62 & -0.16 & -0.14 \\
\hline WCST categories & $5.6(1.1)$ & $5.3(1.2)$ & $5.5(0.8)$ & .51 & .66 & 0.10 & -0.19 \\
\hline perseverative errors & $7.3(6.5)$ & $8.2(6.3)$ & $6.8(5.9)$ & .66 & .42 & -0.08 & -0.23 \\
\hline non pers. errors & $2.1(3.3)$ & $3.0(4.1)$ & $1.9(2.0)$ & .60 & .86 & -0.07 & -0.32 \\
\hline Fluency & & & & & & & \\
\hline Category motor speed corr. (s) & $2.0(1.1)$ & $2.0(1.0)$ & $1.6(0.5)$ & .04 & .04 & -0.46 & -0.48 \\
\hline Letter motor speed corr. (s) & $4.1(1.9)$ & $4.3(1.8)$ & $3.4(0.9)$ & .19 & .04 & -0.47 & -0.60 \\
\hline Psychomotor speed & & & & & & & \\
\hline Stroop A time (s) & $43.3(7.8)$ & $54.2(25.5)$ & $44.7(5.9)$ & .50 & .12 & 0.20 & -0.50 \\
\hline Stroop B time (s) & $55.1(14.2)$ & $68.7(27.0)$ & $55.4(8.7)$ & .93 & .04 & 0.03 & -0.62 \\
\hline Memory & & & & & & & \\
\hline Doors A (visual recognition) & $10.3(2.1)$ & $9.6(1.6)$ & $9.8(1.8)$ & .32 & .80 & 0.25 & -0.12 \\
\hline Doors B (visual recognition) & $6.1(2.0)$ & $6.0(2.6)$ & $7.4(2.4)$ & .06 & .05 & -0.58 & -0.55 \\
\hline 15 words test direct recall & $39.0(12.6)$ & $43.1(10.9)$ & $43.3(7.7)$ & .16 & .95 & -0.41 & -0.02 \\
\hline delayed recall 20' & $7.4(3.8)$ & $9.0(3.5)$ & $8.6(2.7)$ & .23 & .64 & -0.36 & 0.12 \\
\hline recognition & $13.8(1.2)$ & $13.8(1.7)$ & $14.0(1.4)$ & .51 & .64 & -0.15 & -0.12 \\
\hline RBMT story immediate recall & $16.6(5.5)$ & $16.3(6.6)$ & $16.7(4.6)$ & .93 & .82 & -0.02 & -0.07 \\
\hline delayed recall & $12.2(5.0)$ & $13.1(6.3)$ & $12.9(4.5)$ & .63 & .91 & -0.14 & 0.04 \\
\hline Language & & & & & & & \\
\hline Boston naming test & $54.3(5.9)$ & $53.7(5.5)$ & $56.6(1.6)$ & .07 & .02 & -0.53 & -0.67 \\
\hline Visuo-spatial functions & & & & & & & \\
\hline JOLO & $26.2(4.4)$ & $24.8(4.5)$ & $26.1(4.0)$ & .97 & .24 & 0.02 & -0.30 \\
\hline DAT space relations ${ }^{\#}$ & $27.7(18.2)$ & $24.7(20.1)$ & $25.1(17.7)$ & .65 & .93 & 0.14 & -0.02 \\
\hline Mental Rotation^ hand (ms) & $1937(1017)$ & $1808(625)$ & $1897(936)$ & .90 & .71 & -0.04 & 0.10 \\
\hline letter R (ms) & $932(298)$ & $910(329)$ & $841(193)$ & .26 & .41 & -0.37 & -0.25 \\
\hline
\end{tabular}


Values are mean (SD). One sided p-values of $<0.05$ are considered significant (two group t-test), shown in bold. Negative effect sizes reflect impaired performance compared to controls. $(\mathrm{m}) \mathrm{s}=($ milli)seconds. MMSE: Mini-mental state examination; MWCST: Modified Wisconsin Card Sorting Test; Fluency motor speed corr. $=$ motor speed corrected. RBMT: Rivermead Behavioral Memory Test; JOLO: judgement of line orientation; DAT: Differential Aptitude Test. \# ( $\mathrm{n}=19,26,22$ in PMA, ALS and HC) ^ ( $\mathrm{n}=16,23,21$ respectively). $\mathbf{\Upsilon}=$ speed dependent tests, not motor speed corrected.

Frequency of cognitive dysfunction. Individual performance compared with normative data showed three measures that were most frequently impaired in PMA and ALS patients: letter-number sequencing, and immediate and delayed story recall. In the remaining tests the frequency of impairment was 10 percent or lower (figure).

Seventeen percent of PMA patients, $27 \%$ of ALS patients and $4 \%$ of controls, respectively, displayed cognitive impairment defined as a score $>2$ SD below the mean of normative data on at least three neuropsychological tests (table 4). Except for the Stroop interference condition and the RAVLT recognition, impairments on all tests were observed in one or more of the 8 cognitively impaired ALS patients. Tests that showed impairments in at least $50 \%$ of the cognitively impaired PMA and ALS patients were: letter-number sequencing, immediate and delayed story recall. 
Table 4. Number of impaired tests and percentages of patients and controls demonstrating impairments.

\begin{tabular}{cccc}
\hline No. of tests impaired & PMA (\%) & ALS (\%) & HC (\%) \\
\hline 0 & 52,2 & 50 & 75 \\
1 & 17,4 & 20 & 12,5 \\
2 & 13,3 & 3,3 & 8,3 \\
$\geq 3$ & 17,3 & 26,6 & 4,2 \\
\hline
\end{tabular}

Clinical variables associated with cognitive impairment. The cognitively impaired ALS patients had more often bulbar onset, compared to the ALS patients without cognitive impairment $(\mathrm{p}<0.05)$. None of the PMA patients had bulbar onset. One of the 4 cognitively impaired PMA patients and 6 of the 8 cognitively impaired ALS patients had bulbar involvement (not significant). Cognitively impaired ALS and PMA patients, respectively, did not differ from patients without cognitive dysfunction with respect to age, education, HADS total score and subscores, disease duration, ALSFRS-R, predVC and UMNscore. When PMA and ALS patients were analyzed together $(n=53)$, the UMN-score did not differ between patients with and without cognitive impairment, nor did the UMN-score correlate to any neuropsychological test score.

\section{DISCUSSION}

Cognitive dysfunction in PMA This study is the first to demonstrate cognitive dysfunction in a relatively large cohort of PMA patients taking into account the potential negative influence of motor 
impairment and respiratory compromise on the neuropsychological assessment. Group differences between PMA and controls were found for attention/working memory (digit span) and category fluency. Seventeen percent of PMA patients showed cognitive impairment with attention/working memory (letter-number sequencing) and story recall being most frequently abnormal. Some tests showed group effects while they were not the most frequently abnormal tests. This inconsistency may result from a significant proportion of patients that have subclinical levels of impairment (for example in category fluency) yielding group differences, but no individual impairments.

The cognitive impairments in PMA patients, together with similar findings in ALS and PLS patients, suggest that extra-motor cerebral involvement is present in MND regardless of the presence or absence of UMN-signs.[1-3, 27] Indeed, when PMA and ALS patients were analyzed together no correlation between the degree of upper motor neuron signs and the presence of cognitive impairment could be demonstrated in this study. One earlier study also examined cognitive functions in PMA with adaptation of tests to motor impairment and exclusion of patients with respiratory weakness. This study did not show cognitive deficits. However, it may have been underpowered with 12 PMA patients undergoing 8 neuropsychological tests.[5]

In the present study the PMA patients were found to have executive dysfunction with impairments on tests of category fluency and digit span backward. The profile of executive dysfunction is supported by the results of the letter-number sequencing test, a working memory task that was the most frequent abnormal test compared to norm scores in our PMA patients (22\%). This is in agreement with impairments of attention and working memory in patients with ALS in our and other studies. [13, 27-30] Since executive dysfunction, including fluency deficits, has been demonstrated in patients with depression, [31] it is worth mentioning that our PMA patients did not show signs of depression, and no differences in depression or anxiety scores were shown between PMA patients with and without cognitive impairment.

Cognitive dysfunction in ALS: memory It has been suggested that in ALS retrieval is predominantly affected and recognition/encoding is relatively intact. Retrieval requires integrity of the prefrontal 
cortex for its executive component. Indeed, in ALS both prefrontal dysfunction and free recall problems have been shown.[1, 32, 33] However, our findings in ALS patients indicate that in addition to retrieval (story recall), recognition is impaired, as the Doors B test showed group effects in ALS patients compared to controls. The Doors B test does not rely on active retrieval, but on passive recognition and its results are more specifically related to the process of encoding. Therefore, impairments on the Doors B test in ALS patients suggest that encoding deficits may as well underlie memory impairments in ALS. $[1,10,12,13]$. Whether encoding deficits in ALS are related to hippocampus dysfunction or attention deficits, or both, needs to be further studied.

Cognitive dysfunction in ALS: visuospatial functions In the present study no visuospatial abnormalities were found in ALS (nor in PMA) patients compared to controls. We used more sensitive tests (e.g. space relations) compared to earlier studies that employed solely the judgment of line orientation or the Visual Space and Object Perception (VSOP) battery.[1, 27, 34, 35] Therefore, the findings of the present study demonstrate the "frontotemporal" cognitive profile in non-demented ALS, as memory, language and executive dysfunction was observed, while visuospatial dysfunction is absent.[2, 13, 27, 33, 35-37]

Comparison of the cognitive profiles of PMA and ALS In both PMA and ALS patients category fluency deficits were found. Also, in both PMA and ALS patients diverging results regarding executive tests were found: impaired fluency (letter and or category fluency) and normal results on the modified Wisconsin Card Sorting Test and Stroop interference tests. This pattern is in agreement with other neuropsychological studies in ALS $[33,36]$ and it emphasises the different pathways in the executive system which may be selectively involved in MND.[28] In addition to executive deficits, in ALS, but not in PMA, the cognitive profile includes recognition and language deficits.[27, 38] The MMSE was significantly lower in PMA patients but not in ALS patients compared to controls. However, differences between the MMSE scores are negligible and have thus very little clinical significance. In addition the MMSE has a strong ceiling effect in controls, i.e., cognitively normal people perform (almost) perfectly resulting in small variance of scores in controls. 
Bulbar involvement The finding of cognitive impairment in our PMA patients, in whom bulbar symptoms were absent or if they occurred during the course were very mild, corroborates earlier findings that cognitive impairment does occur in MND-patients with isolated limb involvement.[39] The potentially negative effects of dysarthria on neuropsychological measures are therefore not applicable to the great majority of the PMA patients in this study.[1] In our ALS patients cognitive impairment was related to bulbar-onset, but not to bulbar involvement.[11] These results show that in MND-patients bulbar onset predisposes to cognitive impairment, but is not a conditio sine qua non.

Upper motor neuron involvement This study shows that MND patients have cognitive impairments that are not per se related to the presence of UMN signs. One must bear in mind that the absence of (bulbar or spinal) UMN-signs does not exclude UMN-pathology in MND: pyramidal tract pathology in the spinal cord may go undetected in PMA patients and is only identified at autopsy.[9] Indeed, it is interesting to examine whether cognitive deficits predict the development of UMN signs (i.e. ALS). However, this requires a longitudinal study, which is beyond the scope of this paper.

Strengths and limitations Strengths: Firstly, bias due to severe motor impairment, dysarthria and respiratory dysfunction have been minimized in our study-design. Secondly, a wide range of cognitive domains was measured, including three tests assessing different visuospatial abilities. Thirdly, two analytical procedures have been applied to assess cognitive functions, i.e., comparison with normative data, and comparison of neuropsychological performance with a matched control group.

Limitations: Firstly, some normative datasets are of better quality than other datasets, e.g. correction for education is not possible for every test. Secondly, our criterion for respiratory failure was based on the vital capacity only ( $\mathrm{VC}<70 \%$ of predicted value), which is a widely used and validated measure. However, this may not have entirely excluded those patients with incipient respiratory failure. Currently, other methods are known to have a higher sensitivity to asses respiratory failure in MND (e.g. SNIFF nasal inspiratory pressure). Thirdly, patients with MND may complain of fatigue which may influence neuropsychological scores negatively. We tried to exclude fatigue as much as possible by appropriate 
timing and setting of the neuropsychological examination. However, as we did not quantify fatigue we can not completely exclude such an influence on our data.

Finally, as we have taken data from a clinic-based cohort, recruitment-bias may be suspected. However, in the Netherlands the great majority of patients with (suspected) MND and not only the "special" cases, are referred to specialised clinics (e.g. Amsterdam and Utrecht) to verify the diagnosis. We estimate that the proportion of patients that refused to cooperate with the study is about $20-30 \%$.

In conclusion, in this study executive dysfunction and verbal recall deficits are demonstrated in PMA. In ALS similar but more extensive cognitive deficits are found. The cognitive impairments in different MND phenotypes may contribute to understanding the extra-motor involvement and the heterogeneity within the MND spectrum.

\section{Acknowledgements}

This study was supported by a grant from the Netherlands ALS Foundation (JR).

The mental rotation test was developed and kindly provided by Sjoerd J. de Vries and Theo Mulder (Centre for Human Movement Sciences, University Medical Centre Groningen). Theo Mulder is now Director of Research, Royal Netherlands Academy of Arts and Sciences.

We gratefully acknowledge the assistance of Hanneke Börger, Hepke Grupstra (Academic Medical Centre, Amsterdam) and Inge van Beilen (University Medical Centre Utrecht) with the recruitment of the patients. We thank the patients and their partners for their participation and the staff of many neurology and rehabilitation out-patient clinics in the Netherlands, for their hospitality.

The Corresponding Author has the right to grant on behalf of all authors and does grant on behalf of all authors, an exclusive licence (or non-exclusive for government employees) on a worldwide basis to the BMJ Publishing Group Ltd and its Licensees to permit this article (if accepted) to be published in Journal of Neurology, Neurosurgery \& Psychiatry and any other BMJPGL products to exploit all 
subsidiary rights, as set out in our licence (http://group.bmj.com/products/journals/instructions-forauthors/licence-forms).

\section{Reference List}

(1) Massman PJ, Sims J, Cooke N, Haverkamp LJ, Appel V, Appel SH. Prevalence and correlates of neuropsychological deficits in amyotrophic lateral sclerosis. J Neurol Neurosurg Psychiatry 1996;61:450-455.

(2) Ringholz GM, Appel SH, Bradshaw M, Cooke NA, Mosnik DM, Schulz PE. Prevalence and patterns of cognitive impairment in sporadic ALS. Neurology 2005;65:586-590.

(3) Caselli RJ, Smith BE, Osborne D. Primary lateral sclerosis: a neuropsychological study. Neurology 1995;45:2005-2009.

(4) Murphy MJ, Grace GM, Tartaglia MC, Orange JB, Chen X, Rowe A, et al. Cerebral haemodynamic changes accompanying cognitive impairment in primary lateral sclerosis. Amyotroph Lateral Scler 2008;9:359-368.

(5) Wicks P, Abrahams S, Leigh PN, Williams T, Goldstein LH. Absence of cognitive, behavioral, or emotional dysfunction in progressive muscular atrophy. Neurology 2006;67:1718-1719.

(6) Visser J, van den Berg-Vos RM, Franssen H, van den Berg LH, Wokke JH, de Jong JM, et al. Disease course and prognostic factors of progressive muscular atrophy. Arch Neurol 2007;64:522-528.

(7) Kabashi E, Valdmanis PN, Dion P, Spiegelman D, McConkey BJ, Vande VC, et al. TARDBP mutations in individuals with sporadic and familial amyotrophic lateral sclerosis. Nat Genet 2008;40:572-574.

(8) van Es MA, van Vught PW, van KG, Blauw HM, Veldink JH, van den Berg LH. Dpp6 is associated with susceptibility to progressive spinal muscular atrophy. Neurology 2009;72:11841185 .

(9) Ince PG, Evans J, Knopp M, Forster G, Hamdalla HH, Wharton SB, et al. Corticospinal tract degeneration in the progressive muscular atrophy variant of ALS. Neurology 2003;60:12521258 .

(10) Abrahams S, Goldstein LH, Al Chalabi A, Pickering A, Morris RG, Passingham RE, et al. Relation between cognitive dysfunction and pseudobulbar palsy in amyotrophic lateral sclerosis. J Neurol Neurosurg Psychiatry 1997;62:464-472.

(11) Lomen-Hoerth C, Murphy J, Langmore S, Kramer JH, Olney RK, Miller B. Are amyotrophic lateral sclerosis patients cognitively normal? Neurology 2003;60:1094-1097. 
(12) Strong MJ, Grace GM, Orange JB, Leeper HA, Menon RS, Aere C. A prospective study of cognitive impairment in ALS. Neurology 1999;53:1665-1670.

(13) Hanagasi HA, Gurvit IH, Ermutlu N, Kaptanoglu G, Karamursel S, Idrisoglu HA, et al. Cognitive impairment in amyotrophic lateral sclerosis: evidence from neuropsychological investigation and event-related potentials. Brain Res Cogn Brain Res 2002;14:234-244.

(14) Muslimovic D, Post B, Speelman JD, Schmand B. Cognitive profile of patients with newly diagnosed Parkinson disease. Neurology 2005;65:1239-1245.

(15) Fiorio M, Tinazzi M, Aglioti SM. Selective impairment of hand mental rotation in patients with focal hand dystonia. Brain 2006;129:47-54.

(16) Brooks BR, Miller RG, Swash M, Munsat TL. El Escorial revisited: revised criteria for the diagnosis of amyotrophic lateral sclerosis. Amyotroph Lateral Scler Other Motor Neuron Disord 2000;1:293-299.

(17) Neary D, Snowden JS, Gustafson L, Passant U, Stuss D, Black S, et al. Frontotemporal lobar degeneration: a consensus on clinical diagnostic criteria. Neurology 1998;51:1546-1554.

(18) Newsom-Davis IC, Lyall RA, Leigh PN, Moxham J, Goldstein LH. The effect of non-invasive positive pressure ventilation (NIPPV) on cognitive function in amyotrophic lateral sclerosis (ALS): a prospective study. J Neurol Neurosurg Psychiatry 2001;71:482-487.

(19) Cedarbaum JM, Stambler N. Performance of the Amyotrophic Lateral Sclerosis Functional Rating Scale (ALSFRS) in multicenter clinical trials. J Neurol Sci 1997;152 Suppl 1:S1-S9.

(20) Ellis CM, Simmons A, Andrews C, Dawson JM, Williams SC, Leigh PN. A proton magnetic resonance spectroscopic study in ALS: correlation with clinical findings. Neurology 1998;51:1104-1109.

(21) Zigmond AS, Snaith RP. The hospital anxiety and depression scale. Acta Psychiatr Scand 1983;67:361-370.

(22) Cohen J. Statistical power analysis for the behavioural sciences (2nd edn). Hillsdale, NJ: Erlbaum, 1988.

(23) Schmand B, Houx P, de Koning I. Norms for Stroop Color Word Test, Trail making test and Story recall of Rivermead Behavioural Memory Test. Amsterdam: De sectie Neuropsychologie van het Nederlands Instituut van Psychologen. 2003.

(24) Schmand B, Groenink SC, van den DM. [Letter fluency: psychometric properties and Dutch normative data]. Tijdschr Gerontol Geriatr 2008;39:64-76.

(25) Marien P, Mampaey E, Vervaet A, Saerens J, De Deyn PP. Normative data for the Boston naming test in native Dutch-speaking Belgian elderly. Brain Lang 1998;65:447-467.

(26) Lineweaver TT, Bond MW, Thomas RG, Salmon DP. A normative study of Nelson's (1976) modified version of the Wisconsin Card Sorting Test in healthy older adults. Clin Neuropsychol 1999;13:328-347. 
(27) Abrahams S, Goldstein LH, Simmons A, Brammer M, Williams SC, Giampietro V, et al. Word retrieval in amyotrophic lateral sclerosis: a functional magnetic resonance imaging study. Brain 2004;127:1507-1517.

(28) Abrahams S, Leigh PN, Harvey A, Vythelingum GN, Grise D, Goldstein LH. Verbal fluency and executive dysfunction in amyotrophic lateral sclerosis (ALS). Neuropsychologia 2000;38:734747.

(29) Chari G, Shaw PJ, Sahgal A. Nonverbal visual attention, but not recognition memory or learning, processes are impaired in motor neurone disease. Neuropsychologia 1996;34:377-385.

(30) Pinkhardt EH, Jurgens R, Becker W, Molle M, Born J, Ludolph AC, et al. Signs of impaired selective attention in patients with amyotrophic lateral sclerosis. J Neurol 2008;255:532-538.

(31) Landro NI, Stiles TC, Sletvold H. Neuropsychological function in nonpsychotic unipolar major depression. Neuropsychiatry Neuropsychol Behav Neurol 2001;14:233-240.

(32) David AS, Gillham RA. Neuropsychological study of motor neuron disease. Psychosomatics 1986;27:441-445.

(33) Kew JJ, Goldstein LH, Leigh PN, Abrahams S, Cosgrave N, Passingham RE, et al. The relationship between abnormalities of cognitive function and cerebral activation in amyotrophic lateral sclerosis. A neuropsychological and positron emission tomography study. Brain 1993;116:1399-1423.

(34) Talbot PR, Goulding PJ, Lloyd JJ, Snowden JS, Neary D, Testa HJ. Inter-relation between "classic" motor neuron disease and frontotemporal dementia: neuropsychological and single photon emission computed tomography study. J Neurol Neurosurg Psychiatry 1995;58:541-547.

(35) Abrahams S, Leigh PN, Goldstein LH. Cognitive change in ALS: a prospective study. Neurology 2005;64:1222-1226.

(36) Ludolph AC, Langen KJ, Regard M, Herzog H, Kemper B, Kuwert T, et al. Frontal lobe function in amyotrophic lateral sclerosis: a neuropsychologic and positron emission tomography study. Acta Neurol Scand 1992;85:81-89.

(37) Raaphorst J, de Visser M., Linssen WH, de Haan RJ, Schmand B. The cognitive profile of amyotrophic lateral sclerosis: A meta-analysis. Amyotroph Lateral Scler Epub Jan 2009.

(38) Anderson VE, Cairns NJ, Leigh PN. Involvement of the amygdala, dentate and hippocampus in motor neuron disease. J Neurol Sci 1995;129 Suppl:75-78.

(39) Rottig D, Leplow B, Eger K, Ludolph AC, Graf M, Zierz S. Only subtle cognitive deficits in non-bulbar amyotrophic lateral sclerosis patients. J Neurol 2006;253:333-339. 
Figure. Percentages of patients and controls with abnormal scores: lower than 2 SD below the population mean.

Legend to figure: Tests with abnormal scores in less than 5\% of PMA and ALS patients are omitted. 
Figure. Percentages of patients and controls with abnormal scores: lower than 2 SD below the population mean.

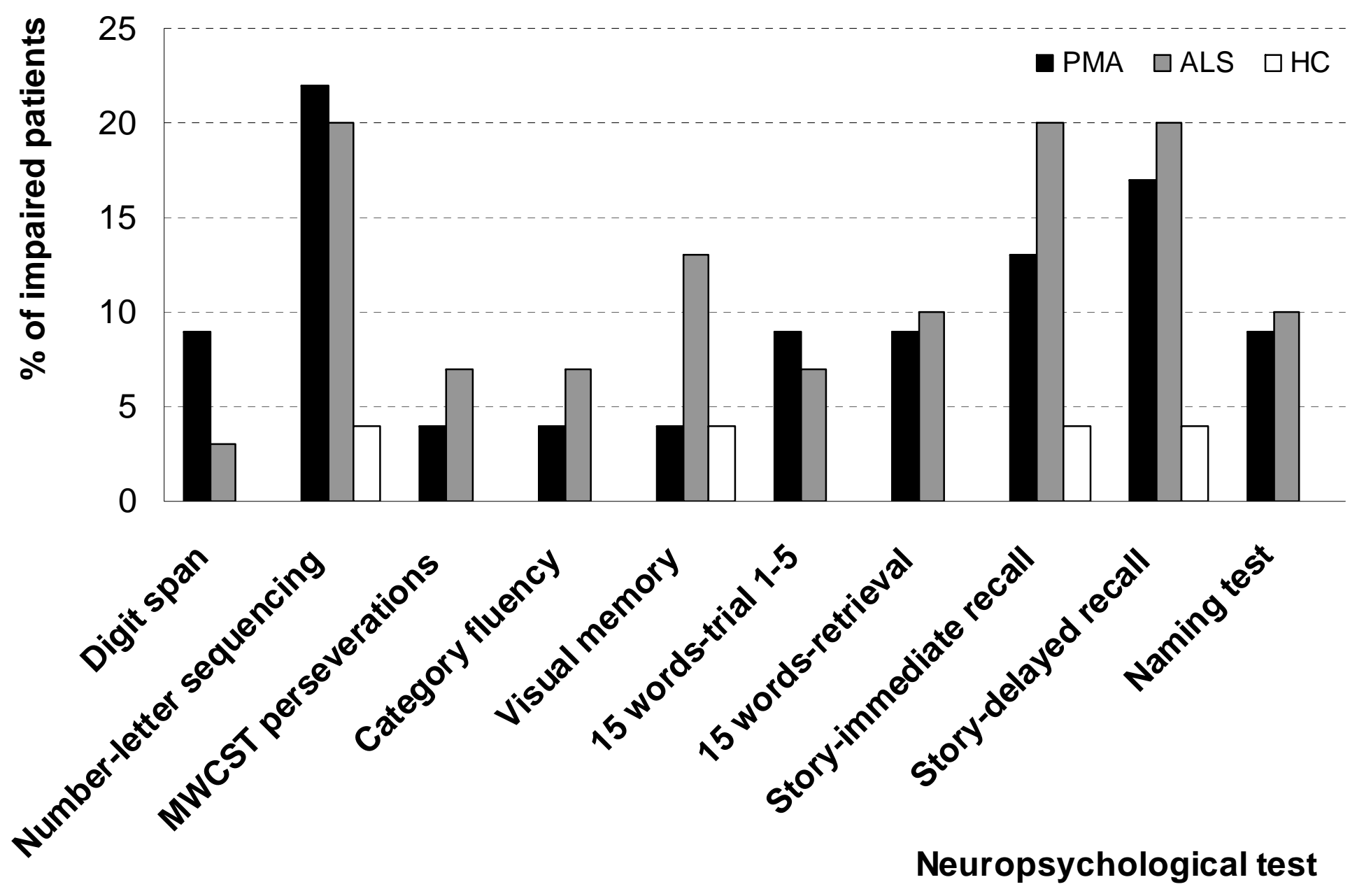

Tests with abnormal scores in less than $5 \%$ of PMA and ALS patients are omitted. 